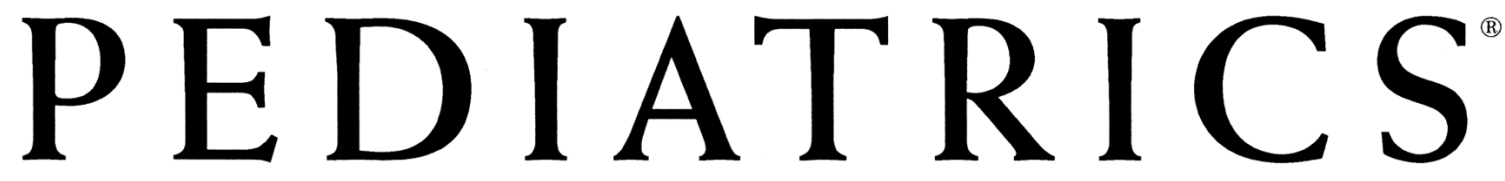

OFFICIAL JOURNAL OF THE AMERICAN ACADEMY OF PEDIATRICS

\title{
An Intervention to Reduce Environmental Tobacco Smoke Exposure Improves Pregnancy Outcomes
}

Ayman A.E. El-Mohandes, Michele Kiely, Susan M. Blake, Marie G. Gantz and M. Nabil El-Khorazaty

Pediatrics published online Mar 8, 2010;

DOI: $10.1542 /$ peds.2009-1809

The online version of this article, along with updated information and services, is located on the World Wide Web at:

http://www.pediatrics.org

PEDIATRICS is the official journal of the American Academy of Pediatrics. A monthly publication, it has been published continuously since 1948. PEDIATRICS is owned, published, and trademarked by the American Academy of Pediatrics, 141 Northwest Point Boulevard, Elk Grove Village, Illinois, 60007. Copyright @ 2010 by the American Academy of Pediatrics. All rights reserved. Print ISSN: 0031-4005. Online ISSN: 1098-4275.

\section{American Academy of Pediatrics}




\section{An Intervention to Reduce Environmental Tobacco Smoke Exposure Improves Pregnancy Outcomes}

AUTHORS: Ayman A. E. El-Mohandes, MBBCh, MD, MPH, ${ }^{a}$ Michele Kiely, DrPH, ${ }^{\mathrm{b}}$ Susan M. Blake, PhD, ${ }^{\mathrm{c}}$ Marie G. Gantz, PhD, ${ }^{\mathrm{d}}$ and M. Nabil El-Khorazaty, PhD ${ }^{\mathrm{d}}$

${ }^{a}$ College of Public Health, University of Nebraska Medical Center Omaha, Nebraska; ${ }^{b}$ Division of Epidemiology, Statistics and Prevention Research, Eunice Kennedy Shriver National Institute of Child Health and Human Development, Bethesda, Maryland; ${ }^{c}$ Department of Prevention and Community Health, George Washington University, Washington, DC; and ${ }^{d}$ Statistics and Epidemiology Unit, Research Triangle Institute (RTI International), Rockville, Maryland

KEY WORDS

behavioral intervention, environmental tobacco smoke, pregnant women, black, birth weight, preterm birth

\section{ABBREVIATIONS}

ETSE- environmental tobacco smoke exposure

RCT—randomized, controlled trial

PNC_- prenatal care

IPV—intimate partner violence

SCL-salivary cotinine level

LBW—low birth weight

VLBW—very low birth weight

PTB - preterm birth

VPTB — very preterm birth

$\mathrm{OR}$ - odds ratio

$\mathrm{Cl}$ - confidence interval

Dr El-Mohandes's former affiliation is Department of Prevention and Community Health, George Washington University, Washington, DC.

This trial has been registered at www.clinicaltrials.gov (identifier NCT00381823)

www.pediatrics.org/cgi/doi/10.1542/peds.2009-1809

doi:10.1542/peds.2009-1809

Accepted for publication 0ct 28, 2009

Address correspondence to Ayman A. E. El-Mohandes, MBBCh, MD, MPH, College of Public Health, University of Nebraska Medical Center, 984355 Nebraska Medical Center, Omaha, NE 68198-4355. E-mail: aelmohandes@unmc.edu

PEDIATRICS (ISSN Numbers: Print, 0031-4005; Online, 1098-4275)

Copyright () 2010 by the American Academy of Pediatrics

FINANCIAL DISCLOSURE: The authors have indicated they have no financial relationships relevant to this article to disclose.

Funded by the National Institutes of Health $(\mathrm{NIH})$
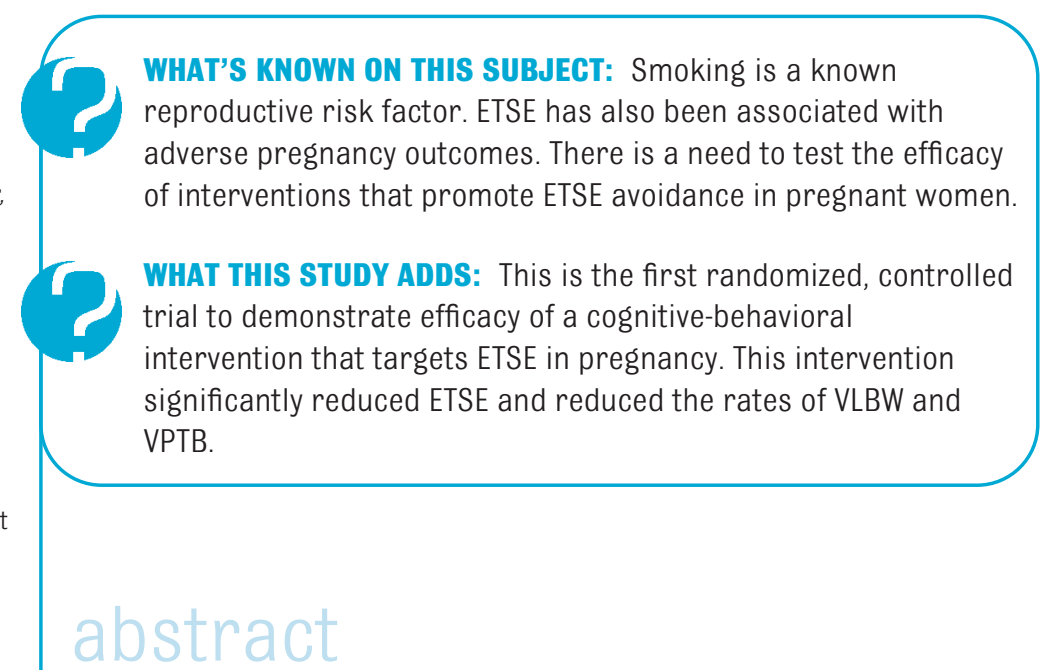

OBJECTIVE: We tested the efficacy of a cognitive-behavioral intervention in reducing environmental tobacco smoke exposure (ETSE) and improving pregnancy outcomes among black women.

METHODS: We recruited 1044 women to a randomized, controlled trial during 2001-2004 in Washington, DC. Data on 691 women with selfreported ETSE were analyzed. A subset of 520 women with ETSE and salivary cotinine levels (SCLs) of $<20 \mathrm{ng} / \mathrm{mL}$ were also analyzed. Individually tailored counseling sessions, adapted from evidence-based interventions for ETSE and other risks, were delivered to the intervention group. The usual-care group received routine prenatal care as determined by their provider. Logistic regression models were used to predict ETSE before delivery and adverse pregnancy outcomes.

RESULTS: Women in the intervention were less likely to self-report ETSE before delivery when controlling for other covariates (odds ratio [OR]: 0.50 [95\% confidence interval (CI): 0.35-0.71]). Medicaid recipients were more likely to have ETSE (OR: 1.97 [95\% Cl: 1.31-2.96]). With advancing maternal age, the likelihood of ETSE was less (OR: 0.96 [95\% $\mathrm{Cl}: 0.93-0.99])$. For women in the intervention, the rates of very low birth weight (VLBW) and very preterm birth (VPTB) were significantly improved (OR: 0.11 [95\% Cl: 0.01-0.86] and 0R: 0.22 [95\% Cl: 0.07-0.68], respectively). For women with an $\mathrm{SCL}$ of $<20 \mathrm{ng} / \mathrm{mL}$, maternal age was not significant. Intimate partner violence at baseline significantly increased the chances of VLBW and VPTB (OR: 3.75 [95\% Cl: 1.02-13.81] and 2.71 [95\% Cl: 1.11-6.62], respectively). These results were true for mothers who reported ETSE overall and for those with an SCL of $<20 \mathrm{ng} / \mathrm{mL}$.

CONCLUSIONS: This is the first randomized clinical trial demonstrating efficacy of a cognitive-behavioral intervention targeting ETSE in pregnancy. We significantly reduced ETSE as well as VPTB and VLBW, leading causes of neonatal mortality and morbidity in minority populations. This intervention may reduce health disparities in reproductive outcomes. Pediatrics 2010;125:721-728 
Disparities in reproductive outcomes represent a significant public health challenge. Characteristics including biological, behavioral, psychosocial, and ecological may contribute to racial/ethnic disparities. ${ }^{1-6}$ Studies have shown the impact of such factors on adverse pregnancy outcomes, including fetal loss, intrauterine growth restriction, preterm birth, birth defects, and infant mortality in black women. ${ }^{7,8}$ Environmental toxicants, such as pesticides and environmental tobacco smoke exposure (ETSE), are hazards that burden socioeconomically challenged communities disproportionately. ${ }^{9}$ The longterm effects of environmental toxicant exposure in utero are exacerbated by circumstances of financial deprivation by those who live in disadvantaged neighborhoods. ${ }^{10}$ The current literature has emphasized the significance of such hazards, but very few studies have attempted to test the efficacy of interventions that aim to reduce their impact on pregnancy outcomes. ${ }^{11,12}$

The prevalence of active smoking among pregnant black women is lower than among pregnant white women (10.6\% vs $18.1 \%) .{ }^{13}$ ETSE during pregnancy, however, may be more frequent as a result of high rates of smoking among black men (26.1\%) and nonpregnant black women (18.5\%). These rates are higher than or equivalent to those reported for white individuals (23.5\% for men and $18.8 \%$ for women). ${ }^{14}$ Black women may be more likely to live in overcrowded households and unable to exert effective control over their living and work environments. ${ }^{15,16}$ Regulations have significantly decreased workplace exposure, but such restrictions do not exist inside the home. The need for evidence-based individualized strategies to help decrease risks of home ETSE during pregnancy is urgent.

In this study, we explored rates of ETSE during pregnancy as self-reported and biologically confirmed in a high-risk population of black women in Washington, DC. We tested the efficacy of a cognitive-behavioral intervention, delivered in this randomized, controlled trial (RCT), comparing women who were randomly assigned to the intervention group with those who received usual care in their ability to avoid ETSE during pregnancy. Comparisons were also made with regard to reproductive outcomes.

\section{METHODS}

The National Institutes of Health-DC Initiative to Reduce Infant Mortality in Minority Populations is a congressionally mandated research project. As part of this project, we recruited women to a multicenter RCT at 6 clinic sites in Washington, DC, between July 2001 and 0ctober 2003 to evaluate the efficacy of an integrated behavioral intervention delivered during prenatal care (PNC) in reducing risk during pregnancy and improving pregnancy outcomes. Women were followed until July 2004. Details of the design of the study and the findings with respect to the primary objectives are presented elsewhere.12,17-19 This study was reviewed and approved by the institutional review boards of the participating institutions.

\section{Study Population}

As described elsewhere, ${ }^{17}$ women were eligible for the study when they self-identified as being an ethnic minority, were $\geq 18$ years, were $\leq 28$ weeks pregnant, were a DC resident, spoke English, and reported at least 1 of the following risk factors: cigarette smoking, ETSE, depression, or intimate partner violence (IPV). A total of 1070 women were eligible, interviewed, and consented for random assignment into the intervention group or the usual-care group. Block randomization was siteand risk-specific. Risks considered in randomization were smoking, depression, and IPV. The field staff were blinded with respect to the block size. Eight women (6 intervention and 2 usual care) were identified as suicidal during intervention or data collection and were referred immediately to mental health care and excluded from additional participation. Of those who remained, 1044 were black and still pregnant at the time of the baseline interview.

The analyses reported in this article are confined to 691 pregnant black women who self-reported ETSE during the initial screening and did not selfreport actively smoking during pregnancy (intervention group $=335$, usual-care group $=356$ ) (Fig 1). ETSE risk was identified when a mother reported exposure to cigarette smoking in her home, same room, or a car with a smoker during a typical week. A more refined subset of 520 women with ETSE and salivary cotinine levels (SCLs) of $<20 \mathrm{ng} / \mathrm{mL}$ at baseline was analyzed separately (intervention group: 247; usual-care group: 273). An SCL of $20 \mathrm{ng} / \mathrm{mL}$ was chosen because this level was associated with 0 median daily cigarettes smoked..$^{20}$ Cutoff levels have been used to differentiate smokers from nonsmokers with ranges between 10 and $20 \mathrm{ng} / \mathrm{mL}^{.15,21-23}$ A detailed description of instruments that were used to assess other risks is available..$^{18}$ Changes in ETSE and other psychobehavioral risks were assessed during telephone interviews conducted in the second and third trimesters (22-26 and 34-38 weeks of gestation, respectively). Interviewers were blinded to the group assignment of participants. Medical risks during pregnancy and pregnancy outcome data on mothers and infants were abstracted from clinic and hospital medical records.

\section{Integrated Behavioral Intervention and Measures}

The intervention arm of this RCT was designed to be delivered during PNC and was based on the behavioral change literature, specific to the des- 


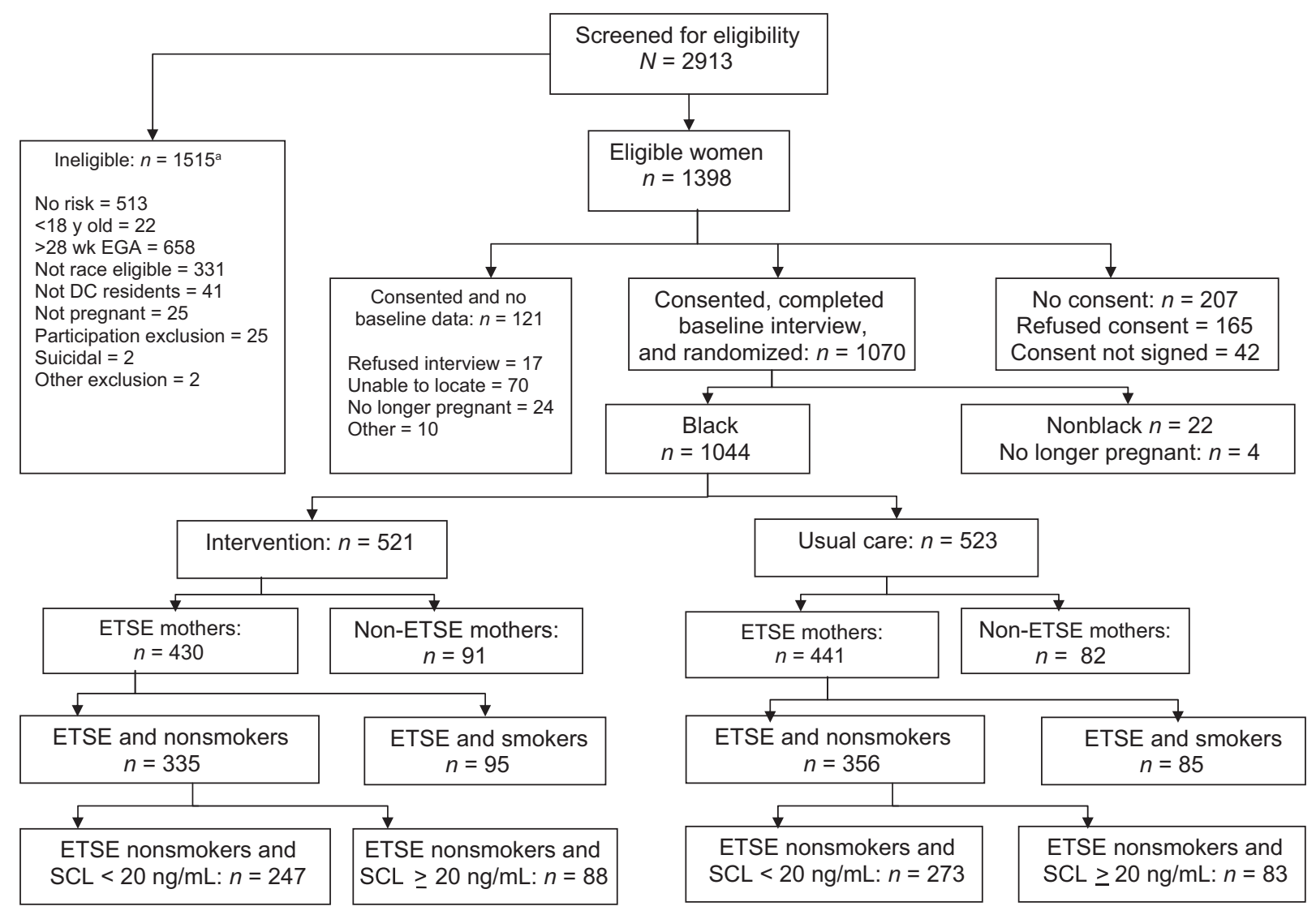

FIGURE 1

Profile of Project DC-HOPE RCT. EGA indicates estimated gestational age. ${ }^{a}$ More than 1 reason for ineligibility may apply.

ignated psychobehavioral risks. ${ }^{18}$ The ETSE intervention focused on introducing strategies within the home to eliminate or minimize exposure of the expectant mother to ETS. Such strategies stressed, through role play and skills practice, the importance of building negotiation skills with partners and other household members who smoked. Mothers were informed about the potential risks of ETS to the mother herself and to her unborn fetus, as well as risks to the newborn. Household smoking bans along with designated safe smoking areas outside the home were encouraged during pregnancy and postpartum. The intervention was delivered by a team of pregnancy advisors who were master'strained psychologists or social workers. The pregnancy advisors were trained on assessing the stage of change of the individual mother and tailoring the intervention to her stage of change.

Mothers who were identified by the Hopkins scale as being depressed received a cognitive behavioral therapy intervention that addressed negative cognition and relationships that contribute to depressive symptoms. Strategies for mood management and increased positive social interaction were the primary focus. Mothers who were identified as experiencing IPV by use of the Conflict Tactics Scale also received a brochure-based intervention that focused on options for developing a personal safety plan and lists of community resources that were provided to all intervention women. The brochure also provided information about the types of abuse (emotional, sexual, and physical) and the cycle of violence (eg, escalation, IPV, honeymoon period). The intervention focused on danger assessment to identify risks for harm and preventive options that women may consider.

Outcome measures included selfreported ETSE before delivery and infant's birth weight and gestational age. Self-reported ETSE was defined as whether a woman was exposed (yes/ no) during the interview before delivery. Infant's birth weight and gestational age were abstracted from the medical records. Low birth weight (LBW) was defined as infant weight $<2500$ g; very low birth weight (VLBW) was defined as infant weight $<1500 \mathrm{~g}$. Gestational age was prioritized in the following order: ultrasound, examination, and menstrual history. Preterm birth (PTB) was defined as gestational age at delivery of $<37$ weeks; very preterm birth (VPTB) was defined as a 
gestational age at delivery of $<34$ weeks.

Cotinine level, the major proximate metabolite of nicotine, was used as a biomarker of tobacco exposure ${ }^{24}$ and was determined by using saliva samples. Cotinine level was then determined by using gas chromatographymass spectrometry with lower detection limits of $10 \mathrm{ng} / \mathrm{mL}$.

\section{Statistical Analysis}

To preserve randomization, we analyzed participant data by using an intention-to-treat approach. Bivariate analyses were conducted to compare the baseline characteristics and pregnancy outcomes in the intervention group versus the usual-care group and to compare groups by self-reported ETSE before delivery and by infant birth weight (LBW/no LBW, VLBW/no VLBW) and preterm status (PTB/no PTB, VPTB/no VPTB). Logistic regression was used to model LBW, VLBW, PTB, VPTB, and ETSE before delivery, controlling for relevant covariates, including care group and other psychobehavioral risks. Initial models to predict birth outcomes (as previously defined) and ETSE before delivery included predictors with a significance level of $<.20$ in the bivariate analyses. Reduced models were then developed retaining care group and covariates with significance of $<.05$. Adjusted odds ratios (ORs) and 95\% confidence intervals (Cls) were produced. Models were constructed for mothers who selfreported ETSE at the initial screening and did not report active smoking at baseline. Additional analyses were conducted for a subset of mothers who had ETSE and whose cotinine level at baseline was $<20 \mathrm{ng} / \mathrm{mL}$.

\section{RESULTS}

Of the 691 mothers who self-reported ETSE and denied actively smoking, approximately one quarter $(27.3 \%)$ had

TABLE 1 Baseline Characteristics of Mothers Who Reported ETSE and No Active Smoking in Pregnancy According to Care Group $(N=691)$

\begin{tabular}{lcr}
\hline \multicolumn{1}{c}{ Characteristic } & $\begin{array}{c}\text { Intervention } \\
(N=335)\end{array}$ & $\begin{array}{c}\text { Usual Care } \\
(N=356)\end{array}$ \\
\hline Maternal age, mean \pm SD, y & $23.4 \pm 4.8$ & $24.1 \pm 5.1$ \\
Education less than high school, \% & 26.3 & 28.4 \\
Employed during pregnancy, \% & 36.1 & 39.9 \\
Marital status married/living with partner, \% & 25.7 & 23.9 \\
Medicaid, \% & 79.6 & 76.3 \\
Early PNC initiation, \% & 61.1 & 57.6 \\
Previous preterm delivery, \% & 12.2 & 9.7 \\
Previous multiple birth, \% & 0.0 & 1.5 \\
Alcohol use during pregnancy, \% & 16.2 & 18.5 \\
Illicit drug use during pregnancy, \% & 10.2 & 7.3 \\
Depression, \% & 40.0 & 39.9 \\
IPV, \% & 31.0 & 29.8 \\
\hline
\end{tabular}

TABLE 2 Behavioral Characteristics Before Delivery According to Care Group for Mothers Who Had ETSE and Did Not Report Active Smoking and Those With an SCL of $<20 \mathrm{ng} / \mathrm{mL}$

\begin{tabular}{lccr}
\hline \multicolumn{1}{c}{ Characteristic } & \multicolumn{2}{c}{ Behavioral Risks Before Delivery } & $P$ \\
\cline { 2 - 3 } & Intervention & Usual Care & \\
\hline All nonsmoking mothers with ETSE, $N$ & 335 & 356 & $<.001$ \\
ETSE, \% & 53.9 & 68.2 & .310 \\
Depression, \% & 32.5 & 36.5 & .020 \\
IPV, \% & 4.7 & 9.9 & .010 \\
All nonsmoking mothers with ETSE and an & 247 & 273 & .510 \\
SCL of $<20$ ng/mL, $N$ & & & .480 \\
ETSE, \% & 53.4 & 66.2 & 34.1 \\
Depression, \% & 31.1 & 7.4 & \\
IPV, \% & 5.7 & & \\
\hline
\end{tabular}

SCLs of $\geq 20 \mathrm{ng} / \mathrm{mL}$ at baseline. When all mothers with an SCL of $\geq 20 \mathrm{ng} / \mathrm{mL}$ were excluded, a more refined subgroup of 520 mothers with ETSE were identified. The baseline characteristics of the 691 women who were randomly assigned to the intervention group and the usual-care group are shown in Table 1. There seemed to be no differences between the 2 groups in sociodemographic, psychosocial, or behavioral characteristics. Results of the intervention group and the usual-care group comparisons of the baseline characteristics for women with ETSE and an SCL of $<20 \mathrm{ng} / \mathrm{mL}$ also showed no differences between the 2 groups (data not shown).

\section{Analyses for Mothers Who Self- reported ETSE and No Active Smoking $(n=691)$}

At the follow-up interview before delivery, rates for ETSE in the interven- tion group were significantly lower than in the usual-care group. The rate of IPV was also significantly lower in the intervention group. No similar effect was seen on rates of depression (Table 2).

Logistic regression models for the 691 predicting ETSE before delivery controlled for the covariates with a significance level of $<.20$ in the bivariate analysis. These covariates were care group, maternal age, marital status, Medicaid, and depression. Reduced Iogistic models were constructed retaining care group and covariates with significance of $<.05$ (Table 3). Women who were randomly assigned to the intervention group were less likely to self-report ETSE before delivery controlling for other covariates (OR: 0.50 [95\% Cl: $0.35-0.71]$ ). In addition, being a Medicaid recipient increased significantly the likelihood of ETSE 
TABLE 3 Reduced Logistic Regression Models for Predicting ETSE Before Delivery

\begin{tabular}{lr}
\hline \multicolumn{1}{c}{ Characteristic } & OR $(95 \% \mathrm{Cl})$ \\
\hline All nonsmoking mothers with & \\
ETSE $(n=691)^{\mathrm{a}}$ & \\
Care group & $0.50(0.35-0.71)$ \\
Maternal age & $0.96(0.93-0.99)$ \\
Medicaid & $1.97(1.31-2.96)$ \\
All nonsmoking mothers with & \\
ETSE and an SCL of $<20$ & \\
ng/mL $(n=520)^{\text {a }}$ & \\
Care group & $0.57(0.38-0.84)$ \\
Medicaid & $1.74(1.11-2.72)$ \\
\hline a Actual numbers used in the analysis are smaller because \\
of missing follow-up data.
\end{tabular}

before delivery. In this group of 691 mothers, as age got older, the risk for ETSE before delivery decreased significantly.

In Table 4, reproductive outcomes were compared by care group. Infant outcome results were available for $82 \%$ of live births for birth weight and $85 \%$ for gestational age. The intervention group had a significantly lower incidence of VLBW and VPTB.

To construct the reduced logistic models, we conducted bivariate analyses comparing mothers who delivered VLBW infants with those who delivered infants who weighed $\geq 1500$ g. Variables in this bivariate comparison included care group, previous preterm delivery, depression, and IPV. Significant differences for mothers who delivered VLBW infants were randomization to the intervention group (10.0\% vs $48.8 \% ; P=.02)$, previous preterm delivery (40.0\% vs $10.9 \% ; P<.01)$, and IPV at baseline $(60.0 \%$ vs $29.4 \%$; $P=$ $.04)$. In the case of VPTB, variables with significant differences included randomization to the intervention group (19.1\% vs $49.5 \%$; $P<.01$ ), previous preterm delivery $(28.6 \%$ vs $11.1 \% ; P=.01$ ), and IPV at baseline (52.4\% vs $29.3 \% ; P=.02)$. For these significant variables, when included in reduced logistic models, randomization to the intervention group significantly reduced the chances of VLBW and VPTB (Table 5). Previous
TABLE 4 Bivariate Comparisons of Pregnancy Outcomes According to Care Group

\begin{tabular}{|c|c|c|c|}
\hline Pregnancy Outcome & $\begin{array}{l}\text { Intervention } \\
(N=335)\end{array}$ & $\begin{array}{l}\text { Usual Care } \\
(N=356)\end{array}$ & $P(N=691)$ \\
\hline \multicolumn{4}{|l|}{ All nonsmoking mothers with ETSE } \\
\hline Miscarriage, \% & 1.4 & 2.8 & .21 \\
\hline Perinatal deaths (20 wk, 28 d), \% & 1.4 & 1.9 & .59 \\
\hline Nonlive birth, \% & 2.7 & 4.7 & .19 \\
\hline Neonatal hospitalization, mean \pm SD, d & $3.1 \pm 3.3$ & $5.5 \pm 22.9$ & .08 \\
\hline LBW (<2500 g), \% & 9.5 & 13.9 & .11 \\
\hline VLBW (<1500 g), \% & 0.4 & 3.1 & .02 \\
\hline PTB (<37 wk), \% & 11.6 & 13.5 & .49 \\
\hline \multirow[t]{2}{*}{ VPTB (<34 wk), \% } & 1.4 & 5.6 & .01 \\
\hline & $\begin{array}{c}\text { Intervention } \\
(N=247)\end{array}$ & $\begin{array}{l}\text { Usual Care } \\
(N=273)\end{array}$ & $P(N=520)$ \\
\hline \multicolumn{4}{|l|}{$\begin{array}{l}\text { All nonsmoking mothers with ETSE and a } \\
\text { baseline } \mathrm{SCL} \text { of }<20 \mathrm{ng} / \mathrm{mL}\end{array}$} \\
\hline Miscarriage, \% & 0.9 & 1.6 & .47 \\
\hline Perinatal deaths (20 wk, 28 d), \% & 1.3 & 1.3 & .93 \\
\hline Nonlive birth, \% & 2.2 & 2.9 & .65 \\
\hline Neonatal hospitalization, mean $\pm S D, d$ & $3.1 \pm 2.8$ & $6.0 \pm 25.6$ & .10 \\
\hline LBW (<2500 g), \% & 11.3 & 12.9 & .59 \\
\hline VLBW (<1500 g), \% & 0.5 & 2.6 & .07 \\
\hline PTB (<37 wk), \% & 11.8 & 13.5 & .59 \\
\hline VPTB (<34 wk), \% & 0.5 & 5.5 & .01 \\
\hline
\end{tabular}

preterm delivery was significantly associated with increased chances of VLBW and VPTB. IPV at baseline significantly increased the chances of VLBW and VPTB.

\section{Analyses for Mothers Who Self- reported ETSE and No Active Smoking and Had an SCL of $<20$ $\mathrm{ng} / \mathrm{mL}(n=520)$}

For this group of mothers, the follow-up interview before delivery also showed rates for ETSE to be significantly lower in the intervention group as compared with the usual-care group. Depression and IPV were not significant (Table 2).

Logistic regression models for the 520 mothers predicting ETSE before deliv- ery controlled for the covariates with a significance level of $<.20$ in the bivariate analysis. These covariates were care group, maternal age, marital status, educational level, Medicaid, and illicit drug use during pregnancy. Reduced logistic models were constructed retaining care group and covariates with a significance of $<.05$ (Table 3). Randomization to the intervention group significantly reduced ETSE before delivery (OR: 0.57 [95\% Cl: $0.38-$ 0.84]). In addition, being a Medicaid recipient increased significantly the likelihood of ETSE before delivery.

Reproductive outcomes were compared by care group. Infant outcome
TABLE 5 Reduced Logistic Regression Models for Predicting VLBW and VPTB

\begin{tabular}{lll}
\hline \multicolumn{1}{c}{ Characteristic } & VLBW, OR $(95 \% \mathrm{Cl})$ & VPTB, OR $(95 \% \mathrm{CI})$ \\
\hline All nonsmoking mothers with ETSE $(N=691)^{\mathrm{a}}$ & & \\
$\quad$ Care group & $0.11(0.01-0.86)$ & $0.22(0.07-0.68)$ \\
$\quad$ Previous preterm delivery & $5.43(1.44-20.55)$ & $3.16(1.15-8.67)$ \\
IPV at baseline & $3.75(1.02-13.81)$ & $2.71(1.11-6.62)$ \\
All nonsmoking mothers with ETSE and a & & \\
$\quad$ baseline SCL of $<20 \mathrm{ng} / \mathrm{mL}(N=520)^{\mathrm{a}}$ & $0.18(0.02-1.49)$ & $0.07(0.01-0.57)$ \\
$\quad$ Care group & - & $2.97(1.00-8.79)$ \\
IPV at baseline & - & \\
\hline
\end{tabular}

${ }^{a}$ Actual numbers used in the analysis are smaller because of missing pregnancy outcomes data. 
results on live births are available for $86 \%$ for birth weight and $88 \%$ for gestational age. Results for the group of 520 showed only VPTB to be significantly different between the 2 groups (Table 4).

To construct the reduced logistic models, we conducted bivariate analyses comparing mothers who delivered VLBW infants with those who delivered infants who weighed $\geq 1500$ g. Variables in this bivariate comparison included care group, previous preterm delivery, depression, and IPV. Significant differences for mothers who delivered VLBW infants were randomization to the intervention group (10.0\% vs $48.8 \%$; $P=.02)$, previous preterm delivery $(40.0 \%$ vs $10.9 \% ; P<.01)$, and IPV at baseline $(60.0 \%$ vs $29.4 \%$; $P=$ .04). In the case of VPTB, variables with significant differences included randomization to the intervention group (19.1\% vs $49.5 \%$; $P<.01)$, previous preterm delivery (28.6\% vs $11.1 \% ; P=.01)$, and IPV at baseline (52.4\% vs $29.3 \%$; $P=.02)$. For this subgroup of mothers, the only significant differences for mothers who delivered VPTB compared with those who delivered infants at $\leq 34$ weeks' gestation were randomization to the intervention group (OR: 0.07 [95\% Cl: 0.01-0.57]) and IPV at baseline (0R: 2.97 [95\% Cl: 1.008.79]) (Table 5).

\section{DISCUSSION}

The built environment and toxicant exposure within it have been shown to represent a disproportionately high health risk to populations who live in poverty. ${ }^{9}$ Our study shows ETSE to be a commonly encountered problem by pregnant black women who may themselves smoke during pregnancy or nonsmokers who live or work with smokers. Of the pregnant black women who were eligible to participate in our study, 3 times as many acknowledged ETSE as compared with women who reported smoking. The lower rates of smoking in pregnancy in black women should not be misinterpreted as an overall low risk for exposure to tobacco smoke.

Our intervention was successful in significantly reducing reported ETSE during pregnancy. The only other factor that was associated with reduced exposure was maternal age. Medicaid (a marker for poverty) was associated with increased exposure. The only other intervention study that attempted to reduce ETSE in pregnancy and of which we are aware was unsuccessful in reaching its goal.11 The author's results agreed with our own in that older mothers seemed to have lower ETSE, although the differences in that study did not reach significance.

ETSE during pregnancy is proved to be strongly associated with poor reproductive outcomes, including elevated rates of LBW. ETSE lowers the infant's adjusted mean birth weight by 33 to $36 \mathrm{~g}$, with a significant dose-response relationship. ${ }^{25,26}$ Factors such as advancing maternal age have been shown to increase the risk for LBW among smokers. ${ }^{27}$ It is unclear what role such modifying factors may play in mothers who are exposed to ETS. Our results do not show an association of VLBW and VPTB with advancing maternal age, but other risks, such as IPV, were associated with increased rates of VLBW and/or VPTB. The history of a previous preterm delivery remains consistently the strongest predictor of VLBW and VPTB among nonsmoking mothers with ETSE.

There seems to be disagreement in the literature regarding the effect of ETSE on gestational age. Two publications showed no association between ETSE and prematurity ${ }^{25,26 ;} 1$ of them, ${ }^{25}$ a large meta-analysis, concluded that there was no effect of ETSE on gestational age. Another study did not show a significant association between ETSE and PTB but found association with the rates of VPTB (adjusted OR: 2.4 [95\% Cl: 1.0-5.3]).27 Our study shows similar results. Our cognitive-behavioral integrated intervention that addressed various risk factors including IPV reduced the rates for VPTB after adjusting for confounders in both groups that were included in these analyses. The intervention showed a significant reduction in VPTB.

The effect of the intervention on the reduction of the higher spectrum of morbidity (VPTB and VLBW) is in itself intriguing. Mothers with the higher level of reproductive morbidity seemed to exhibit the highest rates of psychosocial and behavioral risk. Such mothers may have benefited significantly from the integrated approach that addressed multiple co-occurring risks simultaneously. Our results did not confirm significant changes in the intervention group except in the case of IPV reduction for mothers who reported ETSE and no smoking during pregnancy. Nonetheless, reduction in degree of depression or IPV may not be detectable in our comparisons. Furthermore, a catalystic effect as a result of modest levels of reduction in multiple co-occurring risks may not be captured in a significant reduction in each risk alone. This is a topic that deserves additional study in larger population samples.

The main strengths of our study include the prospective, controlled trial and pregnancy outcomes as the end points. The limitations of the study include its restriction to high-risk black women and the lack of its generalizability to a broader population. The sample size of this study was calculated by using a presumed reduction of the designated risks in the intervention group. The extent of the effect of the intervention on pregnancy outcomes was not part of our assumptions in sample size calculations. This limitation in sample size may have pre- 
vented differences across groups from reaching statistical significance, especially for more rare outcomes. Lower rates of miscarriage and longer hospital stays as well as higher rates of nonlive births and LBW were noted in some subgroup analyses but may not have reached significance as a result of inadequacy of sample size. The nondisclosure of active smoking by $27 \%$ of mothers who self-reported only as ETS exposed is in agreement with other investigators who reported reluctance of pregnant women to share information about smoking during pregnancy. ${ }^{28}$ In addition, the significant results for both all mothers with ETSE and those with an SCL of $<20 \mathrm{ng} / \mathrm{mL}$ are consistent. The chemical confirmation by SCL measurement is reassuring that our findings are valid even for mothers with relatively low levels of salivary cotinine. Additional studies with even lower cutoff points are needed.

\section{REFERENCES}

1. Ehrenthal DB, Jurkovitz C, Hoffman M, Kroelinger C, Weintraub W. A population study of the contribution of medical comorbidity to the risk of prematurity in blacks. $A m J$ Obstet Gynecol. 2007;197(4):409.e1-409.e6

2. Gonzalez-Calvo J, Jackson J, Hansford C, Woodman C. Psychosocial factors and birth outcomes: African American women in case management. J Health Care Poor Underserved. 1998;9(4):395-419

3. Cnattingius S. The epidemiology of smoking during pregnancy: smoking prevalence, maternal characteristics, and pregnancy outcomes. Nicotine Tob Res. 2004;6(suppl 2): $\$ 125-S 140$

4. Orr ST, James FA, Blackmoore Prince C. Maternal prenatal depressive symptoms and spontaneous preterm birth among AfricanAmerican women in Baltimore Maryland Am J Epidemiol. 2002;156(9):797-802

5. Murphy CC, Schei B, Myhr TL, Du Mont J. Abuse: a risk factor for low birthweight? A systematic review and meta-analysis. CMAJ. 2001;164(11):1567-1572

6. DeFur PL, Evans GW, Cohen Hubal EA, et al. Vulnerability as a function of individual and group resources in cumulative risk assessment. Environ Health Perspect. 2007;115(5): 817-824
Our intervention required a specialized staff of master's-level trained social work and mental health professionals who may not be readily available at most PNC sites. Adding comparably trained professionals to a PNC team may present some financial challenges.

Finally, the intervention did not encourage participation of other household members who could have assisted the pregnant mother in negotiating and implementing a household smoking ban. Existing evidence shows the added efficacy of household support in ETS avoidance. ${ }^{15}$

\section{CONCLUSIONS}

Our study is the first, to our knowledge, to show that a cognitive-behavioral intervention that is delivered during PNC can assist black mothers in reducing their risk for ETSE and improving their pregnancy outcomes. A simple screen-

7. Sims M, Sims TL, Bruce MA. Urban poverty and infant mortality rate disparities. J Natl Med Assoc. 2007;99:349-356

8. Wigle DT, Arbuckle TE, Turner MC, et al. Epidemiological evidence of relationships between reproductive and child health outcomes and environmental chemical contaminants. J Toxicol Environ Health B Crit Rev. 2008;11(5-6):373-517

9. Perera FP, Rauh V, Tsai WY, et al. Effects of transplacental exposure to environmental pollutants on birth outcomes in a multiethnic population. Environ Health Perspect. 2003;111(2):201-205

10. Rauh VA, Whyatt RM, Garfinkel R, et al. Developmental effects to exposure to environmental tobacco smoke and material hardship among inner city children. Neurotoxicol Teratol. 2004;26(3):373-385

11. Pletsch PK. Reduction of primary and secondary smoke exposure for low income black pregnant women. Nurs Clin North Am. 2002;37 (2):315-329

12. El-Mohandes AE, Kiely M, Joseph JG, et al. An intervention to improve postpartum outcomes in African American mothers: a randomized controlled trial. Obstet Gynecol. 2008;112(3):611-620

13. Martin JA, Hamilton BE, Sutton PD, et al. ing method that is used in the clinic identified a population at risk. It was evident that the intervention was associated with reduced ETSE and a varying degree of improved pregnancy outcomes. The most consistent association with ETSE reduction was a significant improvement in the rates of VPTB. This is most relevant in the potential impact on the reduction of infant mortality rates because the smallest and most preterm infants are those who are at the highest risk for death and significant morbidity. ${ }^{13,29}$

\section{ACKNOWLEDGMENTS}

This study was supported by grants 3U18HD030445, 3U18HD030447, 5U18HD31206, 3U18HD03919, and 5U18HD036104 from the Eunice Kennedy Shriver National Institute of Child Health and Human Development and the National Center on Minority Health and Health Disparities.

Births: final data for 2005. Natl Vital Stat Rep. 2007;56(6):1-103

14. National Center for Health Statistics. Health, United States, 2007 With Chart Book on Trends in the Health of Americans. Hyattsville, MD: National Center for Health Statistics; 2008

15. Blake SM, Murray KD, El-Khorazaty MN, et al. Environmental tobacco smoke avoidance among pregnant African American nonsmokers. Am J Prev Med. 2009;36(3): 225-234

16. Misra DP, Nguyen RH. Environmental tobacco smoke and low birth weight a hazard in the workplace? Environ Health Perspect. 1999;107 (suppl 6):897-904

17. El-Khorazaty MN, Johnson AA, Kiely M, et al. Recruitment and retention of low-income minority women in a behavioral intervention to reduce smoking, depression, and intimate partner violence during pregnancy. BMC Public Health. 2007:7:233

18. Katz KS, Blake SM, Milligan RA, et al. The design, implementation and acceptability of an integrated intervention to address multiple behavioral and psychosocial risk factors among pregnant African American women. BMC Pregnancy Childbirth. 2008; $8(1): 22$ 
19. Joseph JG, El-Mohandes AA, Kiely M, et al. Results of a randomized clinical trial in high-risk pregnant African American women to reduce psychosocial and behavioral risk factors in pregnancy. Am J Public Health. 2009;99(6):1053-1061

20. El-Mohandes AE, Kiely M, Gantz MG, Blake SM, El-Khorazaty MN. Prediction of birth weight by cotinine levels during pregnancy in a population of black smokers. Pediatrics. 2009;124(4). Available at: www.pediatrics.org/cgi/content/full/124/ 4/e671

21. Hegaard HK, Kjærgaardm H, Møller LF, Wachmann $\mathrm{H}$, Ottesen B. The effect of environmental tobacco smoke during pregnancy on birth weight. Acta Obstet Gynecol Scand. 2006;85(6):675-681

22. Jarvis MJ, Tunstall-Pedeo H, Feyerbend C,
Vesey C, Saloojee Y. Comparison of tests used to distinguish smokers from nonsmokers. Am J Public Health. 1987;77(11): 1435-1438

23. Jarvis MJ, Fidler J, Mindell J, Feyerabend C, West R. Assessing smoking status in children, adolescents and adults: cotinine cutpoints revisited. Addiction. 2008;103(9): 1553-1561

24. Benowitz NL. Biomarkers of environmental tobacco smoke exposure. Environ Health Perspect. 1999;107 (suppl 2):349-355

25. Leonardi-Bee J, Smyth A, Britton J, Coleman T. Environmental tobacco smoke and fetal health: systematic review and metaanalysis. Arch Dis Child Fetal Neonatal Ed. 2008;93 (5):F351-F361

26. Ward C, Lewis S, Coleman T. Prevalence of maternal smoking and environmental tobacco smoke exposure during pregnancy and impact on birth weight: retrospective study using Millennium Cohort. BMC Public Health. 2007;7:81

27. Windham GC, Hopkins B, Fenster L, Swan SH. Prenatal active or passive tobacco smoke exposure and the risk of preterm delivery or low birth weight. Epidemiology. 2000; 11(4):42-433

28. Webb DA, Boyd NR, Messina D, Windsor RA. The discrepancy between self-reported smoking status and urine cotinine levels among women enrolled in prenatal care at four publicly funded clinical sites. J Public Health Manag Pract. 2003;9(4):322-325

29. Dominguez TP. Race, racism, and racial disparities in adverse birth outcomes. Clin Obstet Gynecol. 2008;51 (2):360-370 
An Intervention to Reduce Environmental Tobacco Smoke Exposure Improves Pregnancy Outcomes

Ayman A.E. El-Mohandes, Michele Kiely, Susan M. Blake, Marie G. Gantz and M. Nabil El-Khorazaty

Pediatrics published online Mar 8, 2010; DOI: $10.1542 /$ peds.2009-1809

Updated Information

\& Services

Permissions \& Licensing

Reprints including high-resolution figures, can be found at:

http://www.pediatrics.org

Information about reproducing this article in parts (figures, tables) or in its entirety can be found online at: http://www.pediatrics.org/misc/Permissions.shtml

Information about ordering reprints can be found online: http://www.pediatrics.org/misc/reprints.shtml 